\title{
Pure Red Cell Aplasia Associated with Thymolipoma: Complete Anaemia Resolution following Thymectomy
}

\author{
David Ferreira $\mathbb{D}^{1,2}$ Royston Ponraj, ${ }^{2}$ Adrian Yeung, ${ }^{3}$ and Jillian de Malmanche ${ }^{4}$ \\ ${ }^{1}$ Conjoint Associate Lecturer, University of New South Wales, Sydney, Australia \\ ${ }^{2}$ Medical Department, Medical Registrar, Liverpool Hospital, Elizabeth St., Liverpool, NSW 2170, Australia \\ ${ }^{3}$ Haematology Department, Haematology Advanced Trainee, Liverpool Hospital, Elizabeth St., Liverpool, NSW 2170, Australia \\ ${ }^{4}$ Haematology Department, Haematology Staff Specialist, John Hunter Hospital, Lookout Rd., New Lambton Heights, \\ NSW 2305, Australia
}

Correspondence should be addressed to David Ferreira; dave_7@live.com.au

Received 19 May 2018; Accepted 16 September 2018; Published 9 October 2018

Academic Editor: Sergio Storti

Copyright (c) 2018 David Ferreira et al. This is an open access article distributed under the Creative Commons Attribution License, which permits unrestricted use, distribution, and reproduction in any medium, provided the original work is properly cited.

Pure red cell aplasia is an uncommon cause of anaemia rarely associated with thymoma. A combination of immunosuppressive therapy and thymectomy offers a potential cure. Thymectomy alone rarely results in anaemia resolution. A seventy-three-year-old male with Klinefelter syndrome presented with progressively increasing shortness of breath and anaemia. Serological testing supported primary bone marrow pathology, and a bone marrow biopsy was performed. A pure red cell aplasia was seen on bone marrow examination, and computed tomography of the chest demonstrated a thymoma. Thymectomy was performed, and histology revealed a thymolipoma. Complete anaemia resolution was achieved following thymectomy alone. This suggests that thymomas may directly mediate immune dysregulation resulting in erythroid precursor destruction.

\section{Introduction}

Pure red cell aplasia (PRCA) is a rare cytopenia characterised by a marked reduction of erythroid precursors in the bone marrow. While most cases are idiopathic, there are a number of possible secondary causes. These include lymphoid and myeloid malignancies, autoimmune disease, viral infection, drugs, and thymoma [1].

Thymomas accounts for less than ten percent of all pure red cell aplasia $[1,2]$. The mechanism by which they cause PRCA is incompletely understood. Anaemia is thought to result from a paraneoplastic immune mediated destruction of erythroid precursors [2]. Thymic histological findings are variable and can include medullary thymoma, spindle thymoma, epithelial thymoma, lymphocytic thymoma, thymic carcinoma, and thymolipoma [3, 4]. Treatment involves surgical resection in combination with immunosuppressive therapy, as surgery alone is generally ineffective
$[3,5]$. The authors present a case of pure red cell aplasia secondary to thymolipoma with complete resolution of anaemia following surgical excision alone.

\section{Case Report}

A seventy-three-year-old gentleman presented with progressive shortness of breath over a two-month period. His medical history was significant for Klinefelter syndrome, heart failure with reduced ejection fraction, obstructive sleep apnoea, hypogonadism, haemochromatosis, and secondary polycythaemia requiring 6-12 monthly venesections. Clinical examination was unremarkable. On presentation, he had a normochromic normocytic anaemia with a haemoglobin of $82 \mathrm{~g} / \mathrm{L}$, a reticulocyte count of $2 \times 10^{9} / \mathrm{L}$, and an elevated haptoglobin (Table 1). Vitamin B12, folate, and thyroid-stimulating hormone studies were normal, and serum ferritin was increased (Table 2). These 
TABle 1: Full blood count comparison.

\begin{tabular}{lcccc}
\hline & Normal range & 6 months prior & Admission & 3 months after thymectomy \\
\hline White cells $\left(10^{9} / \mathrm{L}\right)$ & $4.0-11.0$ & 7.5 & 6.4 & 7.0 \\
Red cells $\left(10^{12} / \mathrm{L}\right)$ & $4.5-6.5$ & 5.95 & 2.94 & 4.97 \\
Haemoglobin $(\mathrm{g} / \mathrm{L})$ & $130-180$ & 160 & 0.243 & 150 \\
Haematocrit $(\mathrm{L} / \mathrm{L})$ & $0.38-0.52$ & 0.498 & 79 & 93 \\
Mean cell volume (fl) & $80-100$ & 264 & 354 & 94 \\
Platelets $\left(10^{9} / \mathrm{L}\right)$ & $150-400$ & 5.2 & 4.4 & 252 \\
Neutrophils $\left(10^{9} / \mathrm{L}\right)$ & $2.0-8.0$ & 1.2 & 0.9 & 4.6 \\
Lymphocytes $\left(10^{9} / \mathrm{L}\right)$ & $1.0-4.0$ & 1.0 & 0.9 & 0.4 \\
Monocytes $\left(10^{9} / \mathrm{L}\right)$ & $0.2-1.0$ & 0.1 & 0.1 & 0.1 \\
Eosinophils $\left(10^{9} / \mathrm{L}\right)$ & $0-0.4$ & & \\
\hline
\end{tabular}

TABle 2: Anaemia screen during hospitilisation.

\begin{tabular}{lcc}
\hline & Normal range & Admission \\
\hline Reticulocytes $\left(10^{9} / \mathrm{L}\right)$ & $10-100$ & 2 \\
Vitamin B12 (pmol/L) & $130-850$ & 228 \\
Folate (nmol/L) & $7.0-46.4$ & 26.7 \\
Ferritin (ug/L) & $30-300$ & 1196 \\
Iron (umol/L) & $11-30$ & 57 \\
Transferrin (g/L) & $1.6-3.4$ & 2.4 \\
Transferrin saturation (\%) & $15-45$ & 90 \\
TSH $^{*}(\mathrm{mIU} / \mathrm{L})$ & $0.4-5.0$ & 1.65 \\
$\mathrm{LDH}^{\dagger}(\mathrm{U} / \mathrm{L})$ & $120-250$ & 236 \\
Haptoglobin $(\mathrm{g} / \mathrm{L})$ & $0.3-2.0$ & 2.68 \\
\hline
\end{tabular}

*Thyroid-stimulating hormone; ${ }^{\dagger}$ lactate dehydrogenase.

laboratory results, notably the markedly reduced reticulocyte count, were consistent with reduced production of red cells in the bone.

Bone marrow biopsy demonstrated a marked reduction in erythroid precursors (two percent of the differential) consistent with pure red cell aplasia (Figure 1). Normal granulopoiesis and megakaryopoiesis were evident. Autoimmune screening (ANA, ENA, dsDNA, RF, and anticardiolipin antibodies) and viral screening were negative (hepatitis B, hepatitis C, human immunodeficiency virus, and parvovirus B19). Serum protein electrophoresis and immunosubtraction were negative for monoclonal bands, and flow cytometry was normal. There were no recent medication changes. A chest computed tomography was performed revealing an anterior mediastinal mass consistent with thymoma (Figure 2). An elective thymectomy was arranged with a cardiothoracic surgeon, and intermittent blood transfusions were provided while awaiting surgery.

Thymectomy was performed via a median sternotomy. Histopathology demonstrated normal thymic tissue mixed with mature adipose tissue, diagnostic of thymolipoma. No inflammation, granulomata, or neoplasia was identified. Three weeks following thymectomy, the patients' haemoglobin normalised with a complete resolution of his symptoms. After a year of follow-up, the patients' haemoglobin remains normal, without immunosuppressive therapy or ongoing transfusions.

\section{Discussion}

Thymolipomas account for $2-9 \%$ of all thymic neoplasms [6]. There have been three previous reports of PRCA associated with thymolipoma [3, 7, 8]. In all three cases, patients received both surgical resection and immunosuppressive therapy prior to any improvement in haemoglobin. We present a case of pure red cell aplasia associated with thymolipoma that resolved following thymectomy alone. The mechanism behind anaemia associated with thymolipoma is not understood. Complete resolution following thymectomy suggests that thymolipomas may directly mediate erythroid precursor destruction. The underlying mechanism may be that of immune cell maturation dysregulation and subsequent autoimmune destruction [2]. Thymolipomas are associated with autoimmune diseases including myasthenia gravis, aplastic anaemia, Graves' disease, and lichen planus [9]. Moreover, patients with Klinefelter syndrome have an increased risk for autoimmune disease, associated with the XXY karyotype [10].

This case serves as a reminder that primary bone marrow pathology is differential for every patient presenting with anaemia. Simple serological screening tests provide pivotal information to guide the investigation and management of patients presenting with anaemia. While uncommon, every patient with a PRCA warrants a chest computed tomography to identify a thymoma, as thymectomy offers a potential cure. 


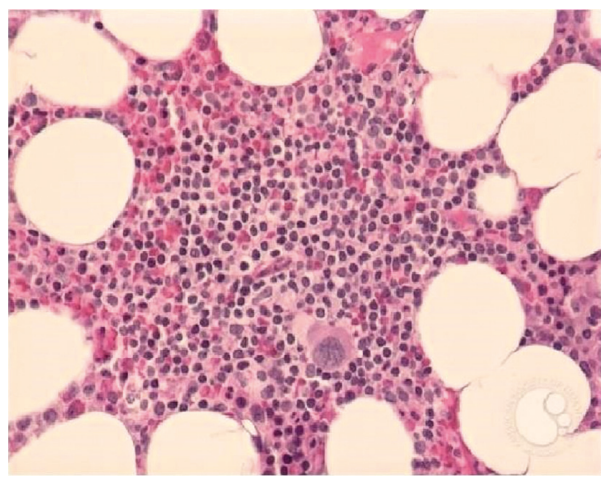

(a)

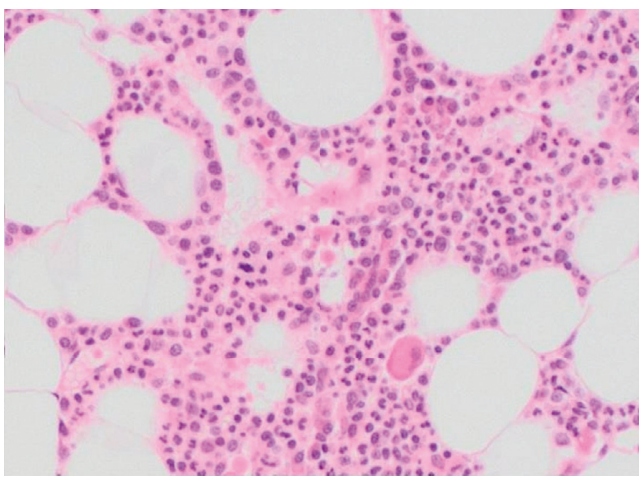

(b)

Figure 1: (a) Normal bone marrow biopsy demonstrating a predominance of erythroid precursors (note cells with round, dark nuclei). This image was originally published in ASH Image Bank. Peter Maslak. Normal adult bone marrow. ASH Image Bank. 2010; Trephine Biopsy-2. (CThe American Society of Hematology. (b) Bone marrow biopsy taken from the patient, demonstrating marked reduction in erythroid precursors.
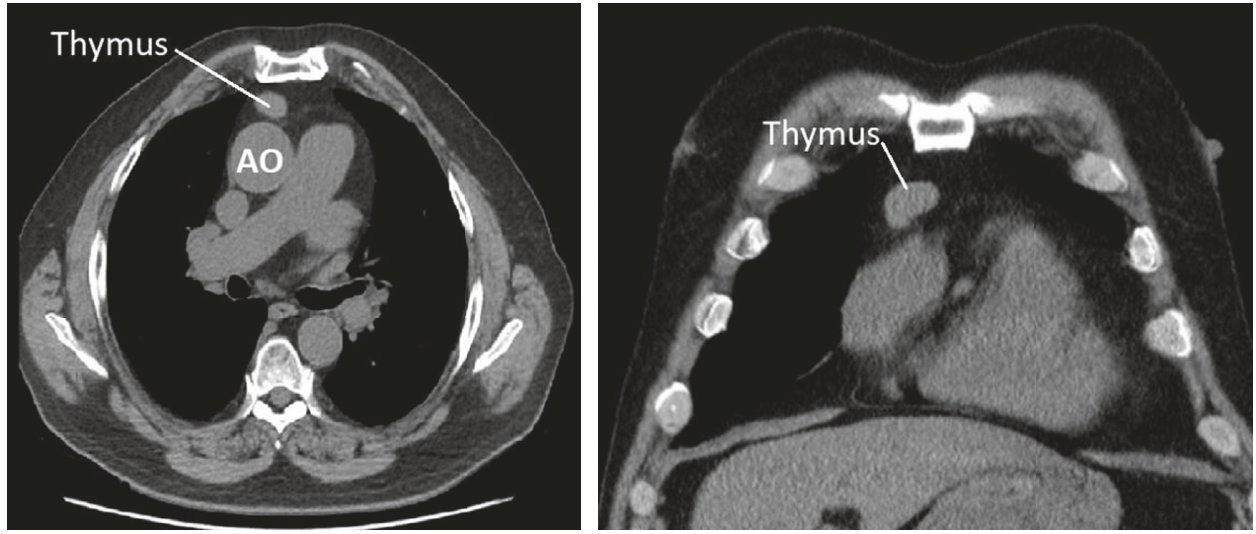

Figure 2: Thymoma on noncontrast chest computed tomography.

\section{Consent}

Verbal consent was provided by the patient with no risk of identification within the manuscript.

\section{Conflicts of Interest}

The authors have no conflicts of interest to declare.

\section{Acknowledgments}

We would like to acknowledge Russell Cox for his valuable assistance in procuring the histological slides.

\section{References}

[1] R. Charles, K. Sabo, P. Kidd, and J. Abkowitz, "The pathophysiology of pure red cell aplasia: implications for therapy," Blood, vol. 87, no. 11, pp. 4831-4838, 1996.

[2] M. Lacy, P. Kurtin, and A. Tefferi, "Pure red cell aplasia: association with large granular lymphocyte leukemia and the prognostic value of cytogenetic abnormalities," Blood, vol. 87, no. 7, pp. 3000-3006, 1996.
[3] C. A. Thompson and D. P. Steensma, "Pure red cell aplasia associated with thymoma: clinical insights from a 50-year single-institution experience," British Journal of Haematology, vol. 135, no. 3, pp. 405-407, 2006.

[4] K. F. Wong, K. F. Chau, J. K. Chan, Y. C. Chu, and C. S. Li, "Pure red cell aplasia associated with thymic lymphoid hyperplasia and secondary erythropoietin resistance," American Journal of Clinical Pathology, vol. 103, no. 3, pp. 346-347, 1995.

[5] C. Rosu, S. Cohen, C. Meunier, D. Ouellette, G. Beauchamp, and G. Rakovich, "Pure red cell aplasia and associated thymoma," Clinics and Practice, vol. 1, no. 1, p. 1, 2011.

[6] M. Nishino, S. K. Ashiku, O. N. Kocher, R. L. Thurer, P. M. Boiselle, and H. Hatabu, "The thymus: a comprehensive review-erratum," RadioGraphics, vol. 37, no. 3, p. 1004, 2017.

[7] K. G. McManus, M. S. Allen, V. F. Trastek, C. Deschamps, T. B. Crotty, and P. C. Pairolero, "Lipothymoma with red cell aplasia, hypogammaglobulinemia, and lichen planus," Annals of Thoracic Surgery, vol. 58, no. 5, pp. 1534-1536, 1994.

[8] E. Lebrun, F. Ajchenbaum, X. Troussard et al., "[Chronic lymphocytic leukemia, erythroblastopenia, thymolipoma]," Nouvelle revue française d'hematologie, vol. 27, no. 1, pp. 29-37, 1985.

[9] R. J. Rieker, P. Schirmacher, P. A. Schnabel et al., "Thymolipoma. A report of nine cases, with emphasis on its 
association with myasthenia gravis," Surgery Today, vol. 40, no. 2, pp. 132-136, 2010.

[10] O. O. Seminog, A. B. Seminog, D. Yeates, and M. J. Goldacre, "Associations between Klinefelter's syndrome and autoimmune diseases: English national record linkage studies," Autoimmunity, vol. 48, no. 2, pp. 125-128, 2015. 


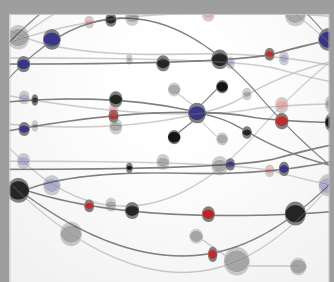

The Scientific World Journal
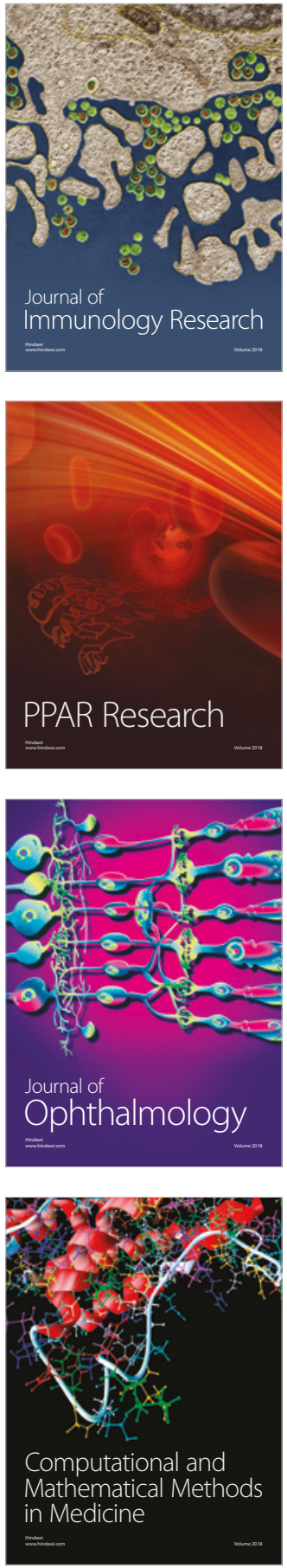

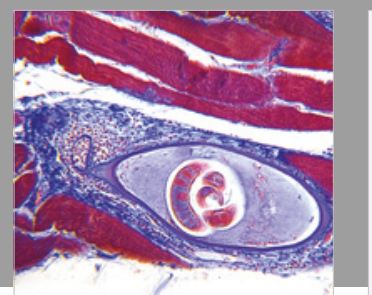

Gastroenterology Research and Practice

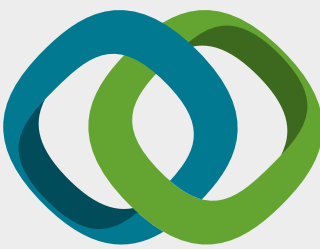

\section{Hindawi}

Submit your manuscripts at

www.hindawi.com
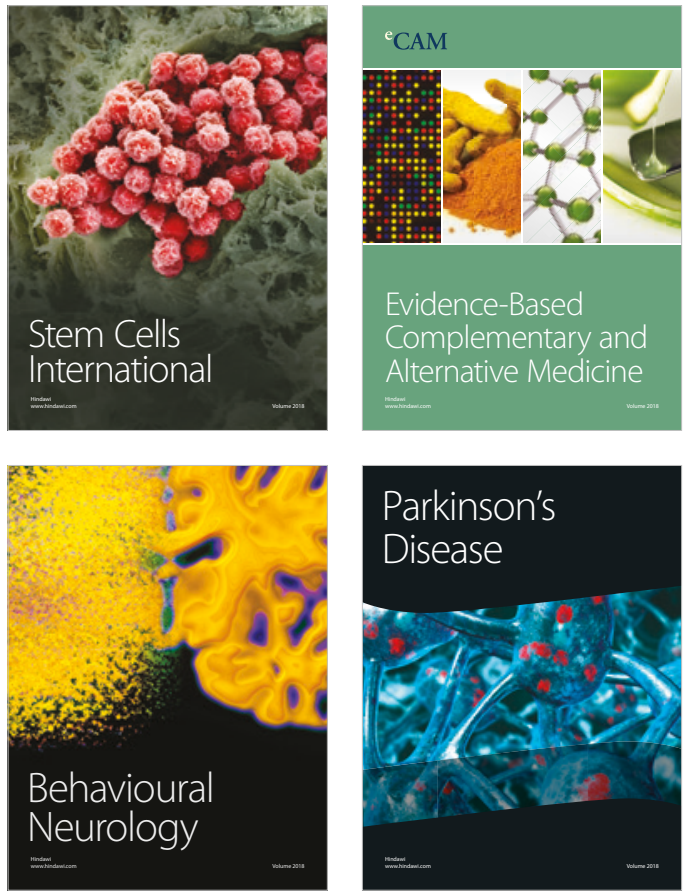

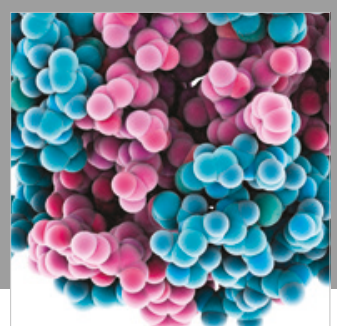

ournal of

Diabetes Research

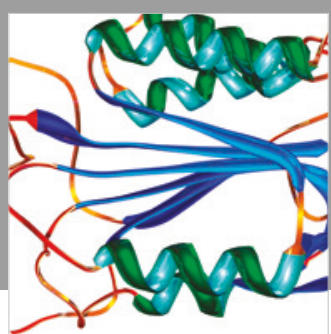

Disease Markers
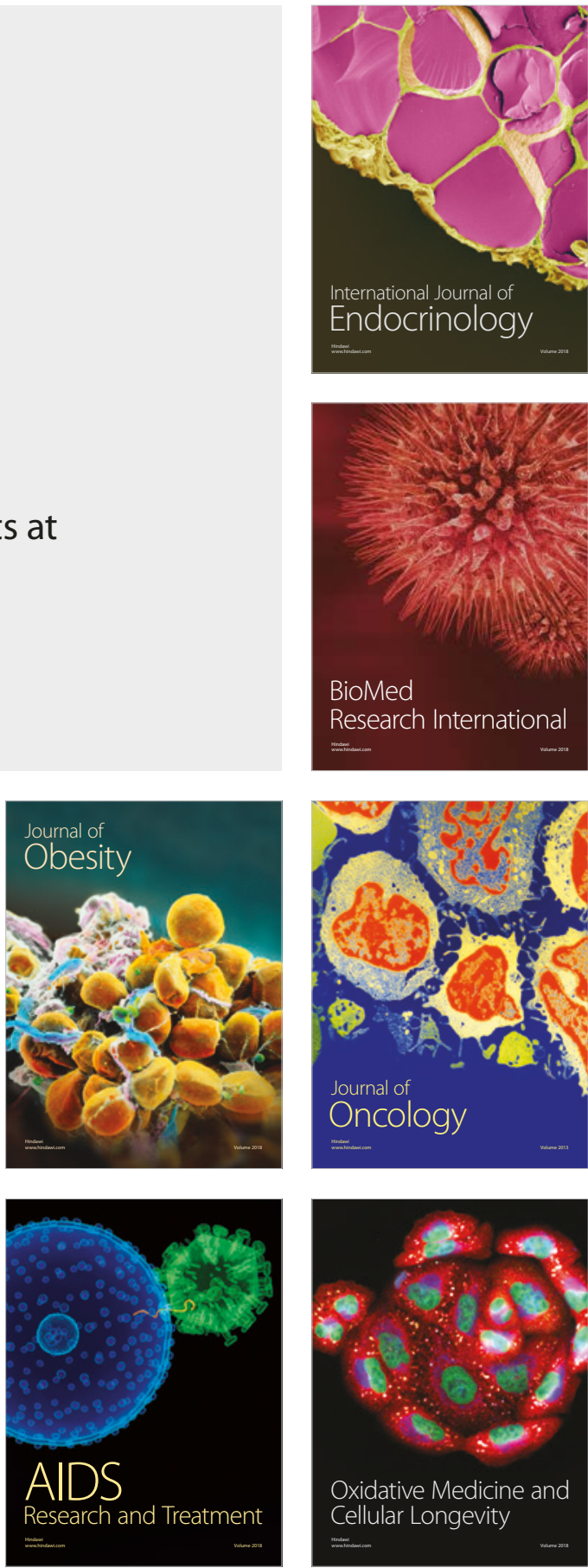